\title{
OBITUARIES
}

\section{Prof. Niels Bjerrum}

WE regret to record the recent death of Niels Bjerrum. He was born in Copenhagen on March 11, 1879 , and studied in the University there, taking the degree of Dr. Phil. in 1908 and presenting a dissertation on the hydrolysis of chromium compounds. This work was extended by the discovery of the third isomeric hexahydrate of chromic chloride and, as a result of a study of the absorption spectra of solutions of chromic salts, by the provision of an experimental foundation for the hypothesis of the complete dissocia. tion of strong electrolytes in solution, which Bjerrum in 1909 was the first to make really significant.

Bjerrum later published many valuable researches in various branches of electrochemistry, the theory of acids and bases, the measurement of hydrogen ion concentrations, amphoteric electrolytes, and the behaviour of indicators. He published a monograph on acid-alkali titration and discovered a simple method of eliminating diffusion potentials in measurements of hydrogen ion concentrations. His work in this field had a very significant influence on the development of the modern theory of electrolytes. He developed a simple equation connecting the activity and osmotic coefficients of an electrolyte, and another one relating the activity coefficients to reaction velocity. He worked with Perrin in 1911 on the Brownian movement and later published work on colloid chemistry. In 1923, he published an important paper on the relation of the stages of ionization of polybasic acids to the molecular structure. In 1911, he related the specific heats of steam and carbon dioxide to band spectra. In 1912, he published work with Nernst on the specific heats of steam and carbon dioxide at high temperatures as determined by the explosion method, and in 1914 he laid the foundations of the theory of the infra-red spectra of polyatomic molecules by introducing the so-called valency force-field, which has led to all subsequent developments in this subject. In these publications he applied the newly developed quantum theory of specific heats to gases.

In 1914, Bjerrum became professor of chemistry in the Royal Danish Veterinary and Agricultural College in Copenhagen, an institution which has had a distinguished history. Since then he has published a large amount of important work in various branches of inorganic and physical chemistry and on problems in agricultural chemistry, notably on the factors which determine the $p \mathrm{H}$ of soils and their fertility. He wrote an excellent small text-book on inorganic chemistry which has gone through several editions, including two in an English translation.

In his prime, Niels Bjerrum was a tall man of handsome presence with an open and friendly expression, and a calm dignity of manner. $\mathrm{He}$ will be greatly missed by his many friends in all parts of the world.

\section{J. R. Partington}

\section{Prof. D. C. Grahame}

David CaLdWELl Grahame, professor of chemistry at Amherst College, Amherst, Massachusetts, U.S.A., died suddenly as a result of a coronary thrombosis in London on December 11. He was spending the academic year as a visiting professor in the University of Bristol.
Prof. Grahame was born in St. Paul, Minnesota, on April 21, 1912. He received a bachelor's degree in chemical engineering at the University of Minnesota in 1935 and a Ph.D. degree in physical chemistry at the University of California at Berkeley in 1937. From then until 1939 he was an instructor in chemistry at Berkeley. From 1939 he was on the staff at Amherst College, becoming assistant professor in 1942, associate professor in 1947 and professor in 1953. He received an honorary M.A. from Amherst in 1953. In 1945 he was a member of the staff of the Radiation Laboratory, Massachusetts Institute of Technology. He taught at Harvard in the summer of 1948. He had visited Europe on several occasions since 1952, having been invited to present papers at meetings of the Deutsche Bunsengesellschaft (1955) and the Chemistry Section of the Soviet Academy of Sciences (1956). He held a Guggenheim Fellowship during his stay in Bristol.

His scientific work was largely in the field of electrochemistry, particularly in the study of the electrical double layer located at the interface between a metal and an electrolytic solution. $\mathrm{He}_{\Theta}$ developed an accurate method of determining the properties of this double layer by measuring its electrical capacity with an alternating current bridge using a growing drop of mercury or gallium as electrode. With this elegant technique he obtained precise results for an extensive variety of electrolytes. Starting from the basic thermodynamic principles, he showed how these results could lead to accurate values of the ionic concentrations at the surface of the electrode and hence to a reliable picture of the structure of the interfacial region. He gave a lucid and comprehensive account of the theory of this procedure in Chemical Reviews in 1947, which was further developed in his paper with Barbara Sodernerg in the Journal of Chemical Physics in 1954.

More recently, Prof. Grahame had turned to the adsorption of poly-electrolytes and the use of nonaqueous solutions. In recent months he had devoted much attention to a study of the distribution of potential in the region within a few Angströms of the surface of the metal. The progress he made in elucidating the latter was only possible on the basis of the precise experimental work in which he excelled, together with the depth of his insight into the theoretical aspects of the problem. It is regrettable that this work remains incomplete.

David Grahame's cheerful friendliness won him friends in all parts of the world, all of whom must grieve at his early death. He was married in 1935 to Virginia Dakin, who survives him, with a son and a daughter.

R. Parsons

\section{Prof. William Brunner}

ON December 1 William Brunner, emeritus professor of astronomy in the University of Zurich and the Swiss Federal Institute of Technology, died in Zurich. Brunner was born in Wattwil (Switzerland) on July 8, 1878. In 1900-after having been a merchant for some years-he began studying astronomy at the Swiss Federal Institute of Technology in Zurich, where in 1904 he acquired the diploma in mathematics and physics. During the next twentytwo years he was a teacher in a girls' college, until in 